\title{
EXPERIMENTAL STUDY OF HEAT TRANSFER ENHANCEMENT WITH WINGLETS INSIDE A TUBE
}

\author{
Guangda Liang, Md. Didarul Islam, Nabil Kharoua \\ Department of Mechanical Engineering \\ The Petroleum Institute \\ Abu Dhabi, UAE \\ guliang@pi.ac.ae,dislam@pi.ac.ae,nkharoua@pi.ac.ae
}

\begin{abstract}
Various technologies have been developing to enhance heat transfer with a lower pressure penalty for an efficient compact heat exchanging devices. Vortex generator is an emerging technology which create longitudinal vortices that does not decay until further downstream and consequently enhance heat transfer rate with comparatively lower pressure penalty. In this research we have experimentally studied heat transfer enhancement and pressure drop inside a tube with winglets vortex generators (VG) insert. Winglets were inserted inside a tube in a circular pattern for different pitch ratios. For this experiment, a constant heat flux was maintained by supplying dc current and accuracy of the heat transfer surface was compared with empirical correlations. The effect of attack angles $\left(0^{\circ}-45^{\circ}\right)$, pitch ratios (1.6-4.8), winglet length $(10 \mathrm{~mm}-20 \mathrm{~mm})$ on heat transfer enhancement pressure penalty were experimentally investigated. The experiments were conducted in a turbulent flow regime with a Reynolds numbers ranging from 6000 to 27000. The experimental results show a significant effect of winglets on the heat transfer and pressure loss over the smooth tube. Results show that increasing the length and the attack angle will intensify both heat transfer coefficient and friction factor. Higher Nusselt number and friction factor were achieved for lower pitch ratio. The contribution of pitch ratio was found more favorable than the length and attack angle on thermal enhancement. Maximum thermal enhancement of 1.17 was achieved for the case of $110 \beta 45$ PR4.8 combination at a lower Reynolds number. Flow structure was also investigated to understand the flow behavior which contributes heat transfer enhancement.
\end{abstract}

\section{INTRODUCTION}

Heat exchangers could transfer heat from one fluid to another and many kinds of heat exchangers are widely used in industrial processes for cooling or heating. They are widely used in different industries such as chemical plants, space heating, refrigeration, power plants, petroleum refineries, and natural gas processing. It's necessary to enhance the performance of heat exchangers by increasing heat transfer coefficient or reducing pressure drop. Application of vortex generator $(\mathrm{VG})$ is one of the most common technologies to augment thermal efficiency of heat exchangers. Vortex generators (winglets, coil wires, tapes and ribs), can generate vortices, enlarge the inner surface of ducts, destabilize the flow field, create secondary flow and aggravate the intensity of turbulence. Longitudinal vortex generator has advantages in augmenting heat transfer performance since the longitudinal vortices continue further downstream. Longitudinal vortex has an axis parallel to the main flow direction while the other type is transverse vortex which axis is perpendicular to the main flow direction. As longitudinal vortex can last for a long distance far down the vortex generators, it has higher thermal enhancement with the same pressure drop. One of early papers published by Biswas et al. [1] reported both numerical and experimental results of thermal behaviour and vortex structure in delta-winglet-fitted rectangular channel. They observed the flow structure and pointed out that longitudinal vortices disrupt the enlargement of boundary layer so that transfer of heat between core flow and near surface flow augment. A three dimensional numerical model was carried out by Jedsadaratanachai et al. [2] to study the thermal behaviour of $45^{\circ}$ delta winglet pairs in a circular duct. Two pairs of winglet induce four main vortices which cause the impinging flow to augment the heat transfer rate. The intensity of flow increases with the increment of winglet height. The heat transfer effect on a tape fitting with double-side winglets into circular duct was experimentally analysed by Yakut et al. [3]. They showed that the prior parameter affects the heat transfer is the Reynolds number. Meanwhile the height of winglet influents the friction factor most. Zhou and Ye [4] experimentally compared the performance of rectangular winglets, trapezoidal winglets and delta winglets. In laminar and transitional regimes, delta winglets show the best result. In the meantime, curved trapezoidal winglet pairs have lower pressure drop performance in turbulent regimes. Some other shape of winglets can also generate longitudinal vortices. Promvonge et al. [5] studied heat transfer characteristic and pressure drop when inclined horseshoe baffle vortex generator inserted at intervals in circular duct. The results showed considerable augmentation of heat transfer and friction loss. Noothong et al. [6] inserted diagonally discrete V-finned tapes into square duct. The reattachment flow created by longitude vortex lead to increment of heat transfer and pressure drop.

For the favourable heat transfer augmentation of vortex generators, the present work is focusing on the flow structure, heat transfer and pressure drop proceeded in an innovative layout. Previous work mainly applied delta winglets in rectangular channel. Few experiments were carried out by mounting delta winglets into circular duct. In this study, the vortex generators were inserted in a circular duct periodically 
with different shapes in turbulent region. Both simulation and experiment were conducted to illustrate the behaviour of vortex generators. Numerical work done through Fluent could provide the details of flow structure and trace the flow path behind vortex generators. Experimental study was proposed to investigate the effect of the parameters of VGs insert in a tube on the performance.

\section{NOMENCLATURE}

\begin{tabular}{lll}
$A$ & {$\left[\mathrm{~m}^{2}\right]$} & Lateral area of the duct \\
$\mathrm{C}_{\mathrm{p}}$ & $\left.\left[\mathrm{Jkg}^{-1} \mathrm{~K}^{-1}\right)\right]$ & Capacity \\
$D$ & {$[\mathrm{~m}]$} & Diameter of the duct \\
$f$ & {$[-]$} & Friction factor \\
$H$ & {$[\mathrm{~m}]$} & Height of winglet vortex generator \\
$h$ & {$\left[\mathrm{Wm}^{-2} \mathrm{~K}^{-1}\right]$} & Convective heat transfer coefficien \\
$I$ & {$[\mathrm{~A}]$} & Current \\
$I_{t u r}$ & {$[-]$} & Turbulence intensity \\
$K$ & {$\left[\mathrm{Wm} \mathrm{K}^{-1}\right]$} & Thermal conductivity \\
$L$ & {$[\mathrm{~m}]$} & Length of test section \\
$l$ & {$[\mathrm{~m}]$} & Length of vortex generator \\
$\dot{m}$ & {$\left[\mathrm{kgs}{ }^{-1}\right]$} & Mass flow rate \\
$N u$ & {$[-]$} & Nusselt number \\
$P$ & {$[\mathrm{~m}]$} & Pitch \\
$P R$ & {$[-]$} & Pitch ratio \\
$\Delta P$ & {$[\mathrm{Pascal}]$} & Pressure drop \\
$P r$ & {$[-]$} & Prandtl number \\
$Q$ & {$[\mathrm{~J}]$} & Heat \\
$R e$ & {$[-]$} & Reynolds number \\
$T$ & {$[\mathrm{~K}]$} & Temperature \\
$U$ & {$\left[\mathrm{~ms}{ }^{-1}\right]$} & Velocity \\
$V$ & {$[\mathrm{volt}]$} & Voltage \\
$\dot{V}$ & {$\left[\mathrm{~m}^{3} \mathrm{~s}^{-1}\right]$} & Volumetric flow rate \\
& & \\
\hline & &
\end{tabular}

Special characters

\begin{tabular}{lll}
$\beta$ & {$\left[{ }^{\circ}\right]$} & Attack angle \\
$\eta$ & {$[-]$} & Thermal enhancement factor \\
$\rho$ & {$\left[\mathrm{kgm}^{-3}\right]$} & Density \\
$v$ & {$\left[\mathrm{~m}^{2} \mathrm{~s}^{-1}\right]$} & Kinematic viscosity \\
\multicolumn{2}{l}{ Subscripts } & \\
air & \\
$b$ & Air \\
conv & bulk \\
$D$ & Convective \\
$i$ & & Duct \\
loss & & Inlet \\
o & & Heat loss \\
O & & Outlet \\
pp & & Smooth duct \\
s & & Pump power
\end{tabular}

\section{EXPERIMENTAL SETUP}

Experimental setup consisted of a blower, orifice meter, flow straightener, calm section and test section. Test section consisted of a copper tube of $52 \mathrm{~mm}$ inner diameter with winglet VGs insert and the length and thickness of tube were $1 \mathrm{~m}$ and 1.75 $\mathrm{mm}$ respectively. A blower with a variac transformer was used for the air flow. Pressure drop is measured by micromanometer which is also used to calculate air flow velocity. The straightener is used to obtain smooth flow before the fluid enters clam section. The length of clam section is $1.5 \mathrm{~m}$ so that it is long enough to generate fully developed flow before the air flows into the test section. Both inlet and outlet pressures are measured by two pressure taps connecting to micromanometer. Data measured by micromanometer is transmitted to computer through NI9205 DAQ. Wire coil was wrapped on the outer surface of test section connecting to a DC supply and a variac transformer to supply constant heat flux in the test section. Wire coil as well as the test section were isolated by thermal insulating material. Two K type thermocouples were located in the inlet and outlet of the tube to record the inlet and outlet temperature, and other 26 thermocouples were placed in holes of the duct surface at equidistant locations to measure the temperature distributions. All of these 28 thermocouples were connected to NI9211 DAQs which is connected to a personal computer to acquire the temperature data. Schematic of the experiment setup is indicated in the Figure 1.

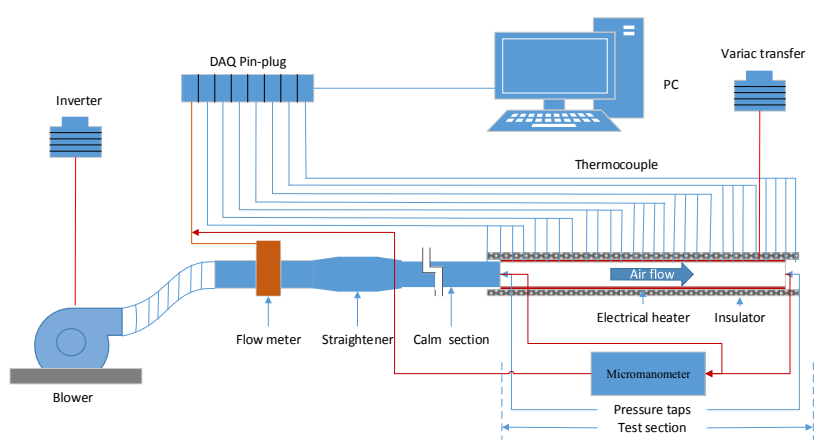

Figure 1 Schematic of experiment setup

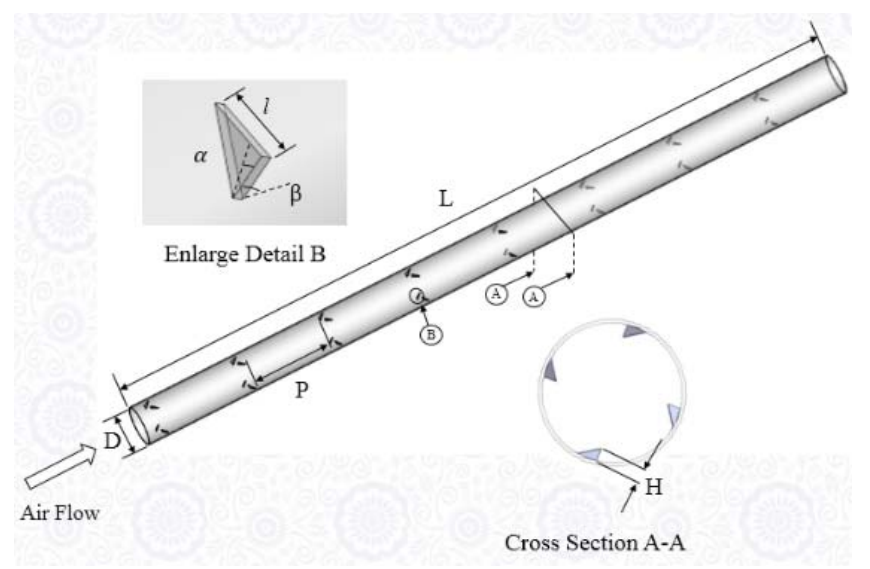

Figure 2 The detail of experimental and numerical test section

Four vortex generators were mounted repeatedly inside the test section with three different pitches $(\mathrm{P}=0.083 \mathrm{~m}, 0.125 \mathrm{~m}$ and $0.25 \mathrm{~m}$ ) which defined as the interval distance of two winglet rings. Thus the pitch ratios $(\mathrm{PR}=\mathrm{P} / \mathrm{D})$ were $1.6,2.4$ and 4.8 respectively. In order to fix the rings, two narrow steel rods $(0.3$ $\mathrm{mm}$ dia) get through the rings to connect them together and then insert the whole set inside the circular tube. The thickness of the winglets was $\mathrm{t}=1 \mathrm{~mm}$. Three lengths $(1=10 \mathrm{~mm}, 15 \mathrm{~mm}$ and $20 \mathrm{~mm})$, three pitch ratio $(\mathrm{PR}=1.6,2.4$ and 4.8) and five attack angle $\left(\beta=0^{\circ}, 10^{\circ}, 20^{\circ}, 30^{\circ}\right.$ and $\left.45^{\circ}\right)$ of vortex generator were studied in this research. The detail of test section is shown in Figure 1\&Figure 2. 


\section{DATA PROCESSING}

The total heat gained by air flow is the convective heat through tube, which is,

$$
\begin{aligned}
& Q_{\text {conv }}=Q_{a i r} \\
& Q_{\text {conv }}=h A\left(\bar{T}_{s}-T_{b}\right) \\
& Q_{a i r}=\dot{m} C_{p, \text { air }}\left(T_{o}-T_{i}\right)=V I-Q_{o s s}
\end{aligned}
$$

Where heat loss $Q_{\text {loss }}$ is approximately $3-5 \%$ considering the isolate layer. And the averaged surface temperature $\bar{T}_{s}$ and bulk temperature $T_{b}$ is computed by,

$$
\begin{aligned}
& T_{b}=\left(T_{o}-T_{i}\right) / 2 \\
& \bar{T}_{s}=\sum T_{s} / 26
\end{aligned}
$$

The average surface temperature is obtained by averaging data measured by 26 thermocouples. By re-arranging the equations above, we have,

$$
h=\dot{m} C_{p} \text {, air }\left(T_{o}-T_{i}\right) /\left(\bar{T}_{s}-T_{b}\right)
$$

Hence the Nusselt number is,

$N u=h D / k$

Reynolds number is,

$\operatorname{Re}=U D / v$

The flow velocity is given by measuring the air flow rate,

$U=4 \dot{V} / \pi D^{2}$

Friction factor refers dimensionless pressure drop for internal flow,

$$
f=\frac{\Delta P}{\left(\frac{L}{D}\right) \rho U^{2} / 2}
$$

Assume that difference of pump power between smooth tube and test tube is negligible. The thermal enhancement factor $(\eta)$, is the ratio of heat transfer coefficient with vortex generator over heat transfer coefficient of smooth tube under the same pumping power, which is suggested by Webb [7]:

$$
\eta=\left.\frac{h}{h_{0}}\right|_{p p}=\left.\frac{N u}{N u_{0}}\right|_{p p}=\frac{N u}{N u_{0}}\left(\frac{f}{f_{0}}\right)^{-\frac{1}{3}}
$$

\section{FLOW STRUCTURE SIMULATION}

The computational domain of circular duct under a constant heat-flux is depicted in Figure 2. A fully developed velocity profile was imposed at the inlet as boundary condition with temperature of $300 \mathrm{~K}$. The turbulence intensity is given as [8],

$$
I_{\text {tur }}=0.16 \mathrm{Re}^{-\frac{1}{8}}
$$

No-slip wall condition was applied to the whole surface while the constant heat-flux condition of $694 \mathrm{Wm}^{-2}$ was imposed on the wall surface.

The height and the length of vortex generators is $5 \mathrm{~mm}$ and $10 \mathrm{~mm}$ respectively in this case of 4.8 -pitch ratio. The assumptions of current numerical model are: three dimensional, steady, incompressible and fully turbulent flow; constant fluid properties; and ignored body force. Based on these assumptions, the model is governed by Navier-Stokes equations with two- equation eddy-viscosity Shear Stress Transport (SST k-omega) model.

The continuity equation is,

$$
\frac{\partial}{\partial x_{i}}\left(\rho u_{i}\right)=0
$$

The momentum equation is,

$$
\frac{\partial}{\partial x_{i}}\left(\rho u_{i} u_{k}\right)=\frac{\partial p}{\partial x_{k}}+\frac{\partial}{\partial x_{i}}\left(\mu \frac{\partial u_{k}}{\partial x_{i}}\right)
$$

The energy equation is,

$$
\frac{\partial}{\partial x_{i}}\left(\rho u_{i} C_{p} T\right)=\frac{\partial}{\partial x_{i}}\left(K \frac{\partial T}{\partial x_{i}}\right)
$$

The SST k-omega transport equations which combines the term of turbulent kinetic energy $\mathrm{k}$ and the term of specific dissipation rate $\omega$.

$$
\begin{aligned}
& \frac{\partial}{\partial x_{i}}\left(\rho k u_{i}\right)=\frac{\partial}{\partial x_{j}}\left(\Gamma_{k} \frac{\partial k}{\partial x_{j}}\right) \\
& \frac{\partial}{\partial x_{i}}\left(\rho \varpi u_{i}\right)=\frac{\partial}{\partial x_{j}}\left(\Gamma_{\varpi} \frac{\partial \varpi}{\partial x_{j}}\right)
\end{aligned}
$$

\section{RESULTS AND DISCUSSION}

\section{Validation of Smooth Duct}

For validation in terms of Nusselt number and friction factor, the results are compared with the correlations given by Petukhov [9] and Gnielinski [10].

The correlation of friction factor,

$$
f=\left(0.790 \ln \operatorname{Re}_{D}-1.64\right)^{-2}
$$

Which is valid when, $3000 \leq \operatorname{Re}_{D} \leq 5 \times 10^{6}$.

And for Nusselt number,

$$
N u_{D}=\frac{(f / 8)\left(\operatorname{Re}_{D}-1000\right) \operatorname{Pr}}{1+12.7(f / 8)^{\frac{1}{2}}\left(\operatorname{Pr}^{\frac{2}{3}}-1\right)}
$$

Which is valid when $0.5 \leq \operatorname{Pr} \leq 2000$, and $3000 \leq \operatorname{Re}_{D} \leq 5 \times 10^{6}$.

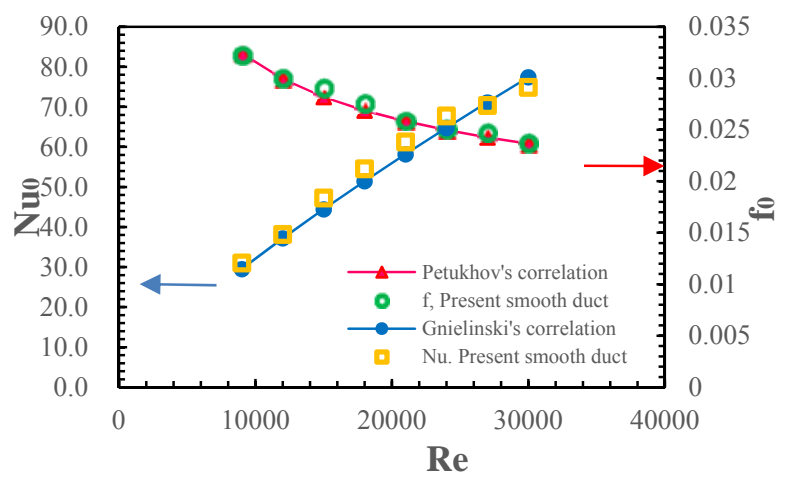

Figure 3 Validation of Nusselt number and friction factor for smooth duct 
Figure 3 shows a comparison between experimental data and empirical correlations with reasonable agreement and the error is in the range of $\pm 5 \%$.

\section{Effect of Length}

The results of three different length of vortex generator were compared in the form of Nusselt number, friction factor and thermal enhancement factor as Figure 4. At a given Re, the Nusselt number would always higher for longer length. This implicates that the longer length could affect greater near-surface flow so that the intensity of heat transfer is greater.

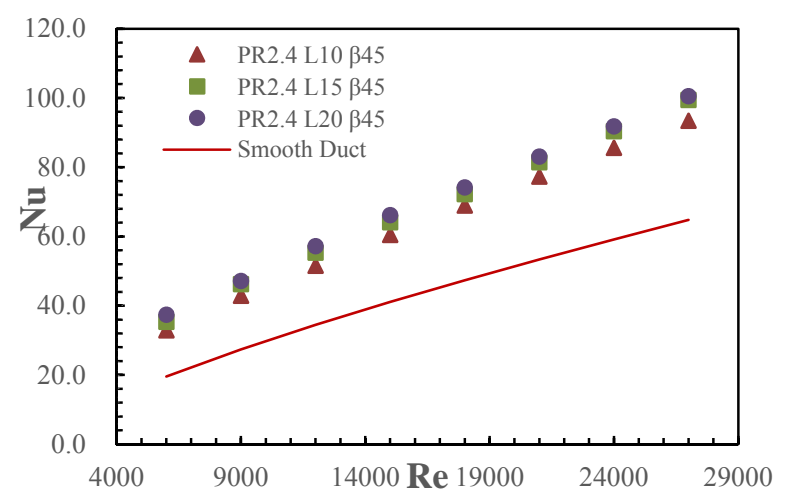

Figure 4 Variation of Nusselt number with Reynolds number for various lengths

For larger influenced field of flow zone, the pressure drop, which is evaluated by friction factor, is inevitably higher. It is demonstrated in Figure 5 that as the length increase, the friction factor also increases.

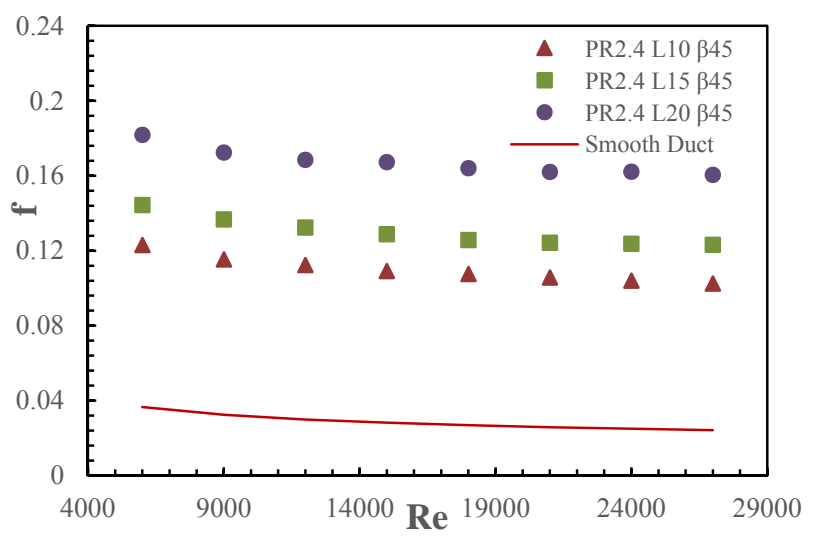

Figure 5 Variation of friction factor with Reynolds number for various lengths

The thermal enhancement factor is displayed in Figure 6. The value of $\eta$ is in the range of $0.827-1.146$ that is higher than unity which indicates thermal performance augmentation. The highest value of 1.146 is found for the length of $15 \mathrm{~mm}$ at low Reynolds number of 6000 .

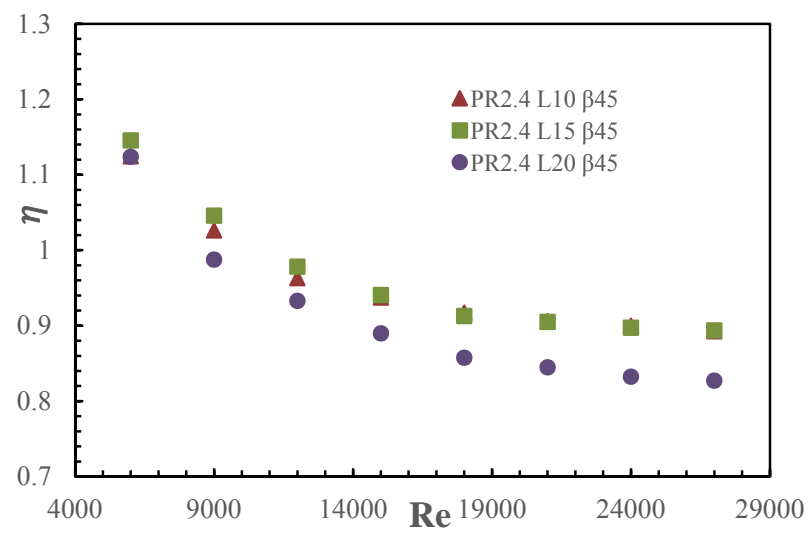

Figure 6 Variation of thermal enhancement factor with Reynolds number for various lengths

\section{Effect of Pitch Ratio}

Figure 7 shows the variation of the Nusselt number with Reynolds number for three pitch ratios ( $\mathrm{PR}=1.6,2.4$, and 4.8). The maximum Nusselt number of 99.4 was found for $L=20 \mathrm{~mm}$, $P R=1.6$ in the Reynolds number of 27000 . The Nusselt number is evidently higher at lower pitch ratio in all ranges. This notes that the flow is repeatedly destabilized by the vortex generator. The lower pitch ratio represents the more frequency of interruption.

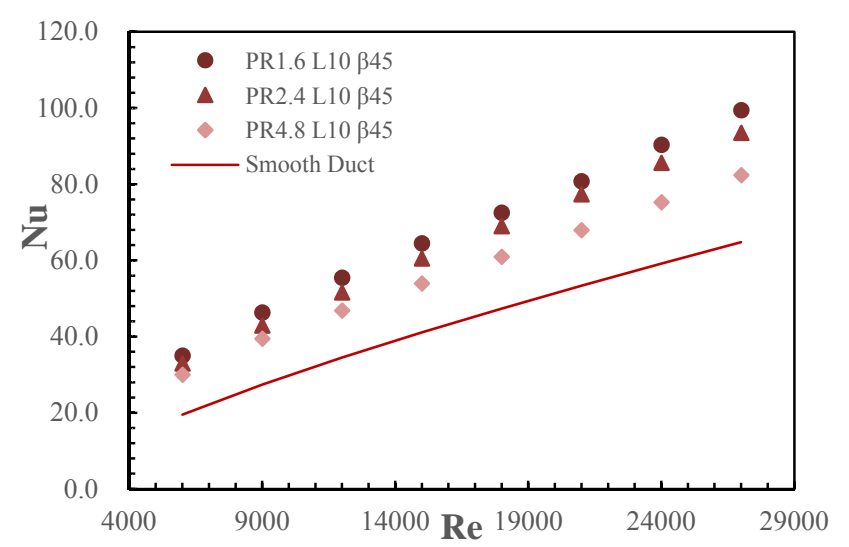

Figure 7 Variation of Nusselt number with Reynolds number for various pitch ratios

The stronger mixing of flow implies that the lager friction factor would achieved. As shown in Figure 8, lower pitch ratio of 1.6, resulted in greatest friction factor at a Reynolds number. The maximum value of friction factor in these cases is 0.159 which is 4.35 times the smooth duct case. 


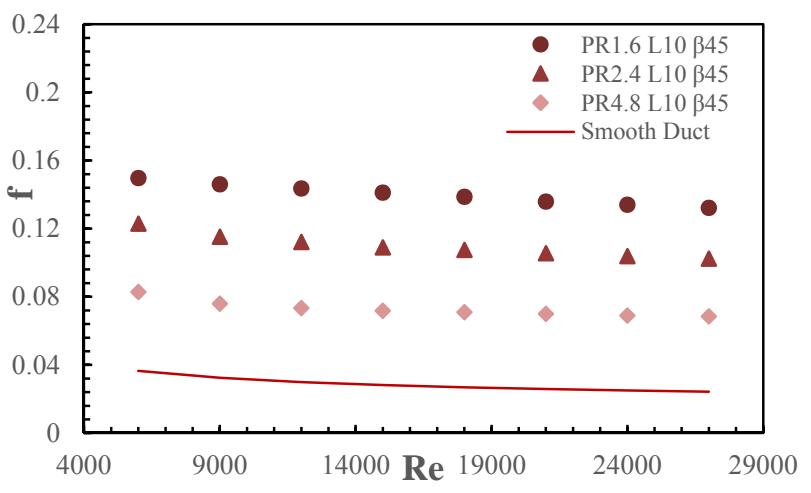

Figure 8 Variation of friction factor with Reynolds number for various pitch ratios

The thermal enhancement factor is also decreasing with the increment of Reynolds number as shown in Figure 9. For a given $\mathrm{Re}$, the value of $\eta$ is greater in larger pitch ratio. It suggests that the penalty of fiction factor is superior to the benefit of heat transfer augmentation. The maximum $\eta=1.17$ is found for the case of $1=10 \mathrm{~mm}$, pitch ratio $=4.8, \operatorname{Re}=6000$, and $\beta=45^{\circ}$.

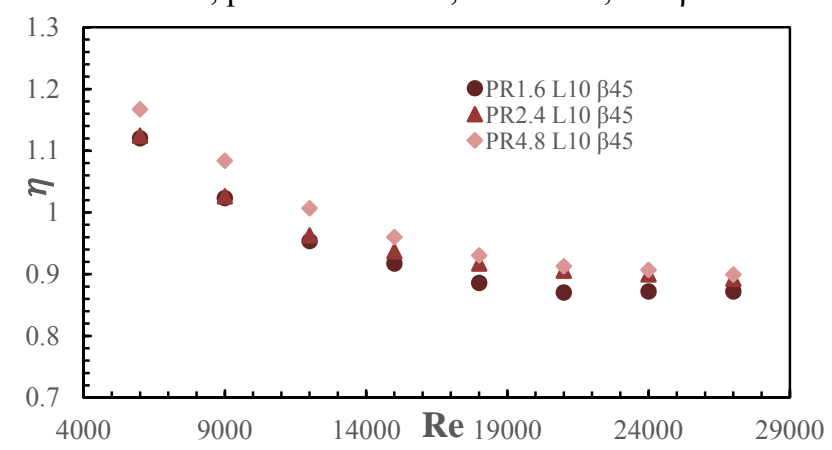

Figure 9 Variation of thermal enhancement factor with Reynolds number for various pitch ratios

\section{Effect of Attack Angle}

The Nusselt number is increasing with the increment of attack angle as shown in Figure 10. The enhancement of heat transfer is rather small for the cases of $0^{\circ}, 10^{\circ}$, and $20^{\circ}$. When the attack angle reaches to $30^{\circ}$, the enhancement is rapidly increased.

This may implicate that the higher attack angle creating the stronger vortex flows and thus enhancing faster fluid mixing between the central core and the near wall regions.

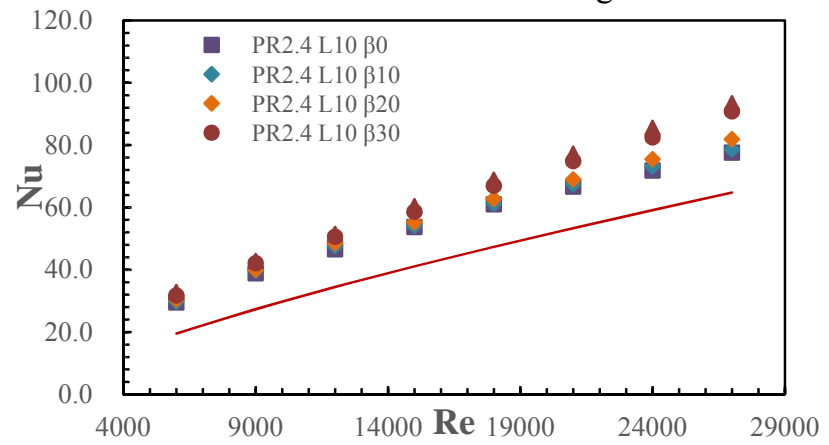

Figure 10 Variation of Nusselt number with Reynolds number for various attack angles
The friction factor is also increasing with the increases of attack angle shown in Figure 11. However, the friction factor is segregated into three distinct zones corresponding to three levels of attack angle (small level of $0^{\circ}$ and $10^{\circ}$, medium level of $20^{\circ}$ and $30^{\circ}$, high level of $45^{\circ}$ ). This shows that the range of attack angle could increases friction factor at various degrees.

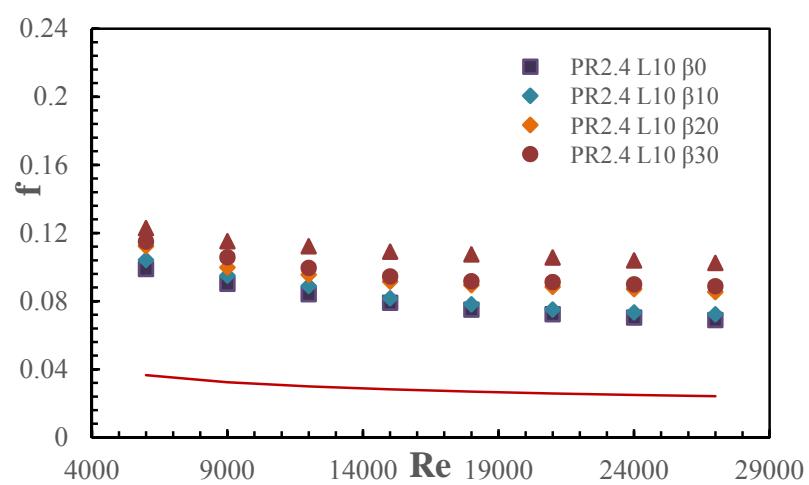

Figure 11 Variation of friction factor with Reynolds number for various attack angles

The thermal enhancement factor is separated for two groups of attack angle. One group is the case of $0^{\circ}, 10^{\circ}$ and $20^{\circ}$ and the other one is $30^{\circ}$, and $45^{\circ}$.

From the

Figure 12, we could summarize that for lower attack angle $\left(0^{\circ}, 10^{\circ}\right.$ and $\left.20^{\circ}\right)$, the thermal enhancement factor is decreasing with the increment of attack angle. It could be attributed to the penalty of friction factor. For the cases of lower attack angle, the improvement of friction factor become dominant over heat transfer augmentation.

Yet the outcome turn inversely for the group of higher attack angle $\left(30^{\circ}\right.$ and $\left.45^{\circ}\right)$. The decline of attack angle would reduce the friction factor that the heat transfer augmentation has come to prevail in terms of overall thermal enhancement evaluation.

It shows the necessity in selecting appropriate value of parameters. It is important to find a balance between the friction factor and Nusselt number for an optimum thermal enhancement factor.

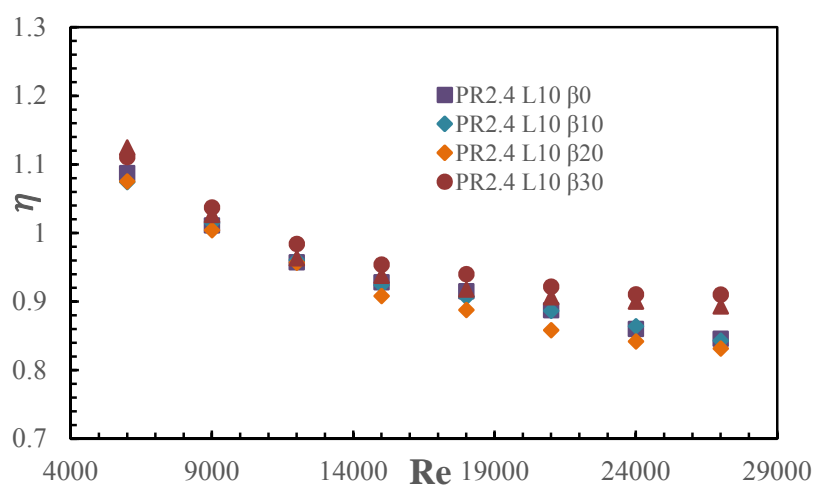

Figure 12 Variation of thermal enhancement factor with Reynolds number for various attack angles 


\section{Numerical Results}

Figure 13 shows the longitudinal vortices generated by the winglets. Vortex generators disrupted the flow layer hence the core fluid flows into near surface, which result in low temperature path lines depicted as rather blue zone.

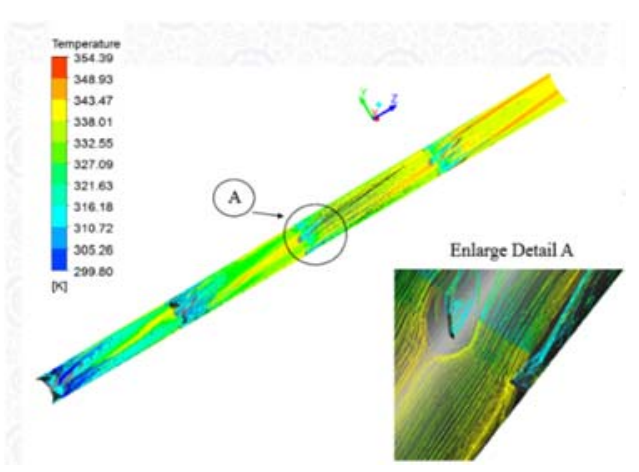

Figure 13 Pathlines released by the vortex generators for $\mathrm{L}=10 \mathrm{~mm}, \mathrm{PR}=4.8, \beta=45^{\circ}$, and $\mathrm{Re}=15000$

The flow structure in the duct mounted repeatedly with the $45^{\circ}$ winglets can be displayed by considering the streamline in transverse planes for $\mathrm{L}=10 \mathrm{~mm}, \mathrm{Re}=15000$ and $\mathrm{PR}=4.8$ as depicted in Figure 14 and Figure 15 for the first interval and the separate planes, respectively. In Figure 14, the locations of transverse cross sections is defined by the $\mathrm{z}$-axis location over the diameter of duct.

The temperature contours and the streamlines in transverse planes are shown in Figure 15. It is visible that four vortices caused by the winglet is appeared. They develop and diminish with the fluid flowing along the tube. All of these vortices shifts in counter-clockwise direction in tube. Connecting with the temperature contours, the peak of the temperature gradient is "dragged up" by the vortex. The phenomenon vividly displayed the procedure which vortices stir the fluid and the adjacent temperature increases.

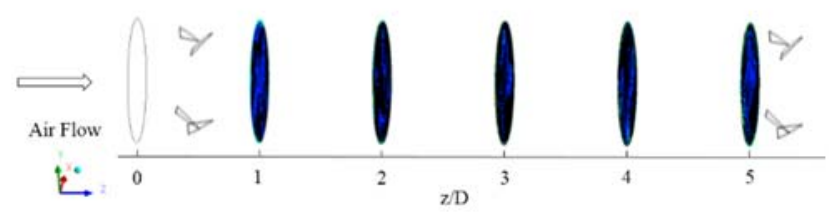

Figure 14 Locations of transverse cross sections

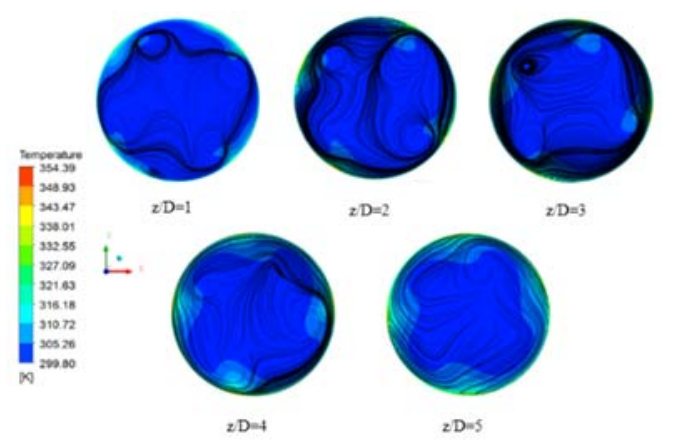

Figure 15 Temperature contours and streamlines in transverse planes

\section{CONCLUSION}

In the current study, thermal performance of delta winglets longitudinal vortex generators were investigated both experimentally and numerically. Delta winglet vortex generators of different lengths, pitch ratio, and attack angle were inserted inside the circular duct. Flow structure is illustrated by the numerical model. The result shows that as the length of vortex generator increase, the heat transfer as well as friction factor increases. The maximum thermal enhancement factor of 1.17 for the case of $1=10 \mathrm{~mm}, \mathrm{PR}=4.8$ and $\beta=45^{\circ}$ at low Reynolds number. As the pitch ratio decrease, both Nusselt number and friction factor raises. The increment of small attack angle would increase the Nusselt number but the thermal enhancement factor will decrease due to the large pressure penalty. However, the decline of large attack angle will increase the thermal enhancement factor for reducing the friction factor. In numerical model, four vortices behind vortex generator appears and they transmit heat by mixing core flow with near-surface flow.

\section{REFERENCES}

[1] Biswas G, Torii K, Fujii D, et al. Numerical and experimental determination of flow structure and heat transfer effects of longitudinal vortices in a channel flow[J]. International Journal of Heat and Mass Transfer, 1996, 39(16): 3441-3451.

[2] Jedsadaratanachai W, Jayranaiwachira N, Promvonge P. 3D numerical study on flow structure and heat transfer in a circular tube with V-baffles[J]. Chinese Journal of Chemical Engineering, 2015, 23(2): 342-349.

[3] Yakut K, Sahin B, Celik C, et al. Effects of tapes with double-sided delta-winglets on heat and vortex characteristics[J]. Applied energy, 2005, 80(1): 77-95.

[4] Zhou G, Ye Q. Experimental investigations of thermal and flow characteristics of curved trapezoidal winglet type vortex generators[J]. Applied Thermal Engineering, 2012, 37: 241-248.

[5] Promvonge P, Tamna S, Pimsarn M, et al. Thermal characterization in a circular tube fitted with inclined horseshoe baffles[J]. Applied Thermal Engineering, 2015, 75: 1147-1155.

[6] Noothong W, Suwannapan S, Thianpong C, et al. Enhanced heat transfer in a heat exchanger square-duct with discrete $\mathrm{V}$-finned tape inserts[J]. Chinese Journal of Chemical Engineering, 2015, 23(3): 490-498.

[7] Webb R L. Performance evaluation criteria for use of enhanced heat transfer surfaces in heat exchanger design[J]. International Journal of Heat and Mass Transfer, 1981, 24(4): 715-726.

[8] Guide A F U. Release 14.0, ANSYS[J]. Inc., November, 2011.

[9] Petukhov B S. Heat transfer and friction in turbulent pipe flow with variable physical properties[J]. Advances in heat transfer, 1970, 6: 503-564.

[10] Gnielinski V. New equations for heat and mass-transfer in turbulent pipe and channel flow $[J]$. International chemical engineering, 1976, 16(2): $359-368$ 